\title{
Risk of Gonadoblastoma Development in Patients with Turner Syndrome with Cryptic Y Chromosome Material
}

\author{
Ahreum Kwon $^{1}$ - Sei Eun Hyun ${ }^{1}$ • Mo Kyung Jung ${ }^{1} \cdot$ Hyun Wook Chae ${ }^{1}$ • \\ Woo Jung Lee ${ }^{1}$ - Tae Hyuk Kim ${ }^{1}$ • Duk Hee Kim ${ }^{2} \cdot$ Ho-Seong Kim ${ }^{1}$
}

Received: 16 December 2016/Accepted: 1 March 2017 /Published online: 27 March 2017

(C) Springer Science+Business Media New York 2017

\begin{abstract}
Current guidelines recommend that testing for $\mathrm{Y}$ chromosome material should be performed only in patients with Turner syndrome harboring a marker chromosome and exhibiting virilization in order to detect individuals who are at high risk of gonadoblastoma. However, cryptic Y chromosome material is suggested to be a risk factor for gonadoblastoma in patients with Turner syndrome. Here, we aimed to estimate the frequency of cryptic Y chromosome material in patients with Turner syndrome and determine whether $\mathrm{Y}$ chromosome material increased the risk for development of gonadoblastoma. A total of 124 patients who were diagnosed with Turner syndrome by conventional cytogenetic techniques underwent additional molecular analysis to detect cryptic Y chromosome material. In addition, patients with Turner syndrome harboring Y chromosome cell lines had their ovaries removed prophylactically. Finally, we assessed the occurrence of gonadoblastoma in patients with Turner syndrome. Molecular analysis demonstrated that 10 patients had $\mathrm{Y}$ chromosome material among 118 patients without overt Y chromosome (8.5\%). Six patients with overt Y chromosome and four patients with cryptic Y chromosome material underwent oophorectomy. Histopathological analysis revealed that the occurrence of gonadoblastoma in the total group was $2.4 \%$, and gonadoblastoma occurred in one of six patients with an overt Y chromosome (16.7\%) and 2 of 10 patients with cryptic Y chromosome material (20.0\%). The risk of developing gonadoblastoma in patients with cryptic $\mathrm{Y}$ chromosome material
\end{abstract}

Ho-Seong Kim

kimho@yuhs.ac

1 Department of Pediatrics, Severance Children's Hospital, Endocrine Research Institute, Yonsei University College of Medicine, 50-1

Yonsei-ro, Seodaemun-gu, Seoul 120-752, South Korea

2 Sowha Children's Hospital, Seoul 140-829, South Korea was similar to that in patients with overt $\mathrm{Y}$ chromosome. Therefore, molecular screening for $\mathrm{Y}$ chromosome material should be recommended for all patients with Turner syndrome to detect individuals at a high risk of gonadoblastoma and to facilitate proper management of the disease.

\author{
Abbreviations \\ TS Turner syndrome \\ FISH fluorescence in situ hybridization
}

\section{Introduction}

Turner syndrome (TS) is a chromosomal disorder characterized by short stature, ovarian failure, and endocrine or congenital anomalies [1]. The incidence of TS is approximately one in 1500-2500 female births [2]. About half of all patients with TS have a 45,X karyotype, and the other half have a partial X chromosome or mosaicism [3, 4]. In general, the Y chromosome has been confirmed by cytogenetic analysis in approximately $6-9 \%$ of patients with TS [5]. Many studies, however, have reported that $4-38 \%$ of patients with TS bear incompletely derived $\mathrm{Y}$ chromosome material, as determined by molecular analyses or fluorescence in situ hybridization (FISH) [6-10].

Detection of cryptic Y chromosome material is essential because the risk of developing gonadoblastoma or other germ cell tumors is increased in Y chromosome-positive patients. The risk of gonadoblastoma development in Y chromosomepositive patients, as confirmed by cytogenetic studies, is approximately $22-43 \%[11,12]$. Therefore, prophylactic oophorectomy has conventionally been recommended for $\mathrm{Y}$ chromosome-bearing patients with TS [13]. However, the clinical significance of cryptic $\mathrm{Y}$ chromosome material in 
patients with TS, detectable only by DNA analysis or FISH, is unclear and is still under investigation. A meta-analysis of 11 studies analyzing the association between $\mathrm{Y}$ chromosome material and gonadoblastoma reported five cases of gonadoblastoma in 43 patients with TS bearing Y chromosome cell lines (11.6\%; in the analyzed patients with TS; the $\mathrm{Y}$ chromosome was detected by cytogenetic analysis in 16 individuals and by molecular analysis in 27 individuals) and a low prevalence of gonadoblastoma $(0.9 \%)$ in the entire patient group (five gonadoblastoma cases of 557 patients with TS) [13]. Based on these data, routine polymerase chain reaction (PCR) examination in patients with TS to detect individuals at high risk of gonadoblastoma is not clinically warranted at present. The Turner Syndrome Consensus Study Group recommended that testing for $\mathrm{Y}$ chromosome material should only be performed in patients with TS harboring a marker chromosome or exhibiting virilization [3].

The present study was performed to assess the occurrence of gonadoblastoma in patients with TS and to investigate the frequency of cryptic Y chromosome material in these patients, allowing us to compare the risk of gonadoblastoma development in patients with TS with overt $Y$ chromosome and patients with TS harboring PCR-verified cryptic Y chromosome material.

\section{Patients and Methods}

\section{Study Population}

Patients who were diagnosed with TS using conventional cytogenetic techniques were recruited through the pediatric endocrine outpatient clinic at Severance Children's Hospital in Seoul, South Korea between 2011 and 2014. Phenotypic female patients with TS were included in this study. Exclusion criteria included any other genetic abnormalities, any other disorders of sexual development, and any malignancies other than gonadoblastoma. This study was approved by the Severance Institutional Review Board (register no. 4-2011-0517), and a total of 124 patients and their parents or legal guardians provided written informed consent after receiving oral and written information concerning the study (Fig. 1). Patient age ranged from 4 to 36 years. The karyotype distribution in the study population is presented in Table 1. Medical records of clinical characteristics, including dysmorphic features, short stature, delayed puberty, osteopenia, and other abnormalities, as well as karyotyping results were reviewed. Dysmorphic features were defined as frequent external characteristics, including short webbed neck, low hairline, low-set ears, broad chest, multiple pigmented nevi, cubitus valgus, swollen or puffy hands or feet, and knuckle knuckle sign. Short stature was defined as a height below 2 standard deviations compared with individuals of the same sex and age in the normal Korean population. Delayed puberty was defined as cases with no breast development by chronologic age 13. Even though breast development was normal, cases with no spontaneous menstruation for 5 or more years after the first appearance of breast tissue were also defined as delayed puberty. For patients under 18 years, osteopenia was defined as $z$-score under -1.0 relative to the same age and sex in bone mineral density. For patients 19 years or older, osteopenia was defined as a $T$-score lower than -1.0 in bone mineral density.
Fig. 1 Flow diagram depicting the frequency of cryptic $\mathrm{Y}$ chromosome material and the occurrence of gonadoblastoma in patients with TS

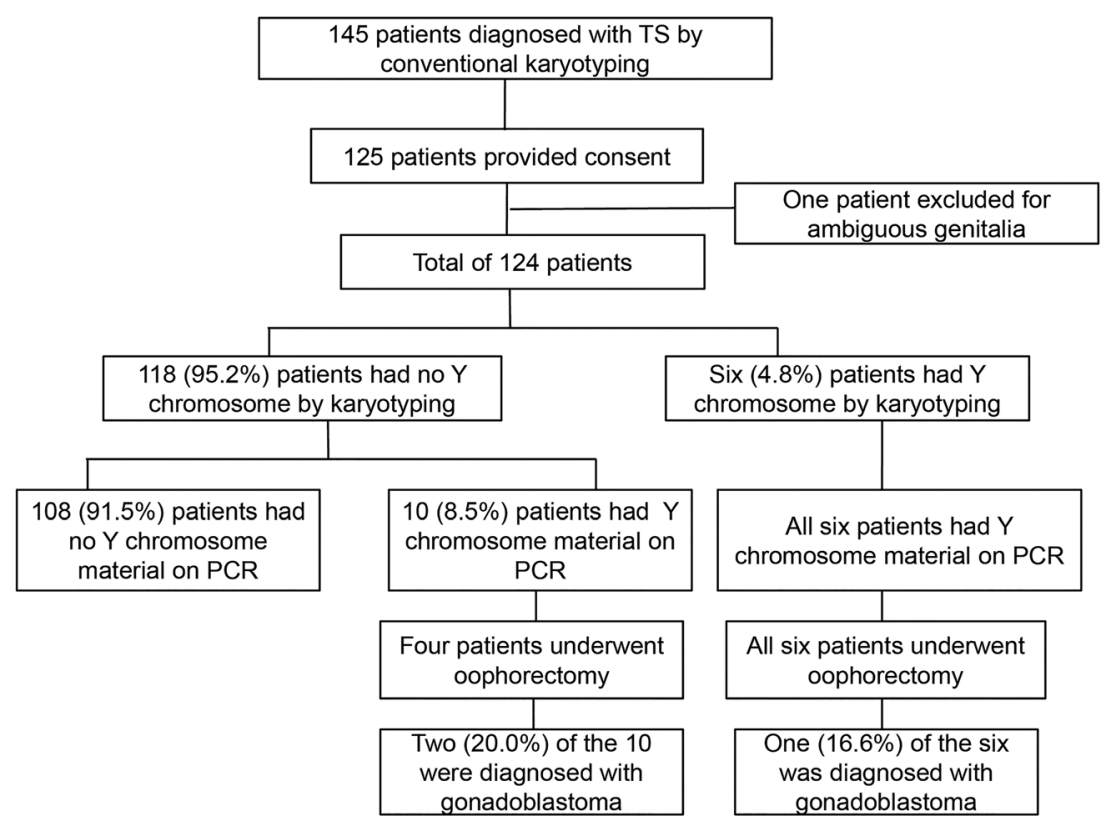


Table 1 Distribution of karyotypes in 124 patients with TS recruited for this study

\begin{tabular}{lc}
\hline Karyotype & $n(\%)$ \\
\hline 45,X; 45,X,inv.(9); 45, X,9p+ & $41(33.1)$ \\
45,X/46,XX; 45,X/47,XXX; 45,X/46,XX/47,XXX & $17(13.7)$ \\
45,X/46,X,i(Xq);46,X,i(Xq); & $34(27.4)$ \\
45,X/46,XX/46,X,i(Xq); 45,X/46,X,idic(Xq) & \\
45,X/46,X,del(X); 46,X,del(X) & $6(4.8)$ \\
+ Ring or marker & $20(16.1)$ \\
45,X/46,XY & $6(4.8)$ \\
Total & $124(100)$ \\
\hline
\end{tabular}

\section{Cytogenetic Analysis}

Karyotypes were determined on metaphase chromosome preparations obtained from peripheral blood lymphocytes using standard procedures. Cytogenetic analysis was performed using the GTG-banding technique. At least 30 metaphase cells were analyzed for each patient.

\section{Molecular Genetic Analysis}

Genomic DNA was extracted from whole blood samples obtained from 124 patients using a QIAamp DNA Blood Midi Kit (Qiagen, CA, USA) according to the manufacturer's instructions. Fourteen Y chromosome-specific sequences located in both arms of the Y chromosome were used to detect cryptic Y chromosome material by PCR analysis. Primer sequences were designed as described previously with minor modifications [14] (Table 2). PCR was performed with $20 \mu \mathrm{L}$ of PCR amplification reaction mixture containing $10 \times$ Ex Taq DNA polymerase buffer with $2.5 \mathrm{mM}$ of each dNTP, $0.5 \mathrm{mM}$ of each primer, $500 \mathrm{ng}$ DNA, and 2.5 U Taq DNA polymerase (Takara Bio, Otsu, Japan). Amplification was performed in duplicate with a PTC-200 thermocycler (MJ Research) using the following profile: $94{ }^{\circ} \mathrm{C}$ for $5 \mathrm{~min}$; 35 cycles of $95^{\circ} \mathrm{C}$ for $30 \mathrm{~s}, 50^{\circ} \mathrm{C}$ for $30 \mathrm{~s}$, and $72^{\circ} \mathrm{C}$ for $30 \mathrm{~s}$; and final extension at $72{ }^{\circ} \mathrm{C}$ for $10 \mathrm{~min}$. PCR products were separated by $1 \%$ agarose gel electrophoresis. All DNA extractions and PCR were performed by a female researcher to avoid the risk of male DNA contamination. For the five patients tentatively diagnosed as Y chromosome-positive by PCR with only one or two primer pairs, the presence of Y chromosome material was further verified and confirmed by direct sequencing after eluting the band on agarose gels to exclude falsepositive reactions. Subsequently, PCR products were purified for sequencing analysis using a gel elution kit (Qiagen, CA, USA) with reference to the respective size. DNA sequencing reactions were carried out using the same primer pairs. The purified PCR products were sequenced using an ABI 3700
Table 2 Primers used in this study

\begin{tabular}{|c|c|c|c|}
\hline Primer & Sequence & $\begin{array}{l}\text { Annealing } \\
\text { temperature }\left({ }^{\circ} \mathrm{C}\right)\end{array}$ & Product size (bp) \\
\hline$P A B Y$ & 5'-GCGCCTATAGTGCCAGCTAC-3' & 62 & 368 \\
\hline$S R Y$ & $\begin{array}{l}\text { 5'-TGAGGGTCAGGCTGCTATTT-3' } \\
\text { 5'-TACAGGCCATGCACAGAGAG-3' }\end{array}$ & 55 & 179 \\
\hline DYZ1 & $\begin{array}{l}\text { 5'-TCTTGAGTGTGTGGCTTTCG-3' } \\
\text { 5'-CCGTTCACATCAATTCCTTG-3' }\end{array}$ & 56 & 368 \\
\hline DYS231 & $\begin{array}{l}\text { 5'-TGAAATGGAATCGAACCACA-3' } \\
\text { 5'-GGGATTGCAGAGAGCAAAAG-3' }\end{array}$ & 55 & 159 \\
\hline DYS209 & $\begin{array}{l}\text { 5'-GCCGTGTGCTGGAGACTAAT-3' } \\
\text { 5'-TTGGTTCCATGCTCCATACA-3' }\end{array}$ & 60 & 180 \\
\hline$Y R R M$ & $\begin{array}{l}\text { 5'-CTCCGAATGTTGCTCCAAAT-3' } \\
\text { 5'-GAGGGCCTCGGATGTCTTAT-3' }\end{array}$ & 55 & 198 \\
\hline DYS224 & $\begin{array}{l}\text { 5'-TACCACATGCTTCACGAGGA-3' } \\
\text { 5'-GTCTGCCTCACCATAAAACG-3' }\end{array}$ & 55 & 301 \\
\hline$A M G Y$ & $\begin{array}{l}\text { 5'-ACCACTGCCAAAACTTTCAA-3' } \\
\text { 5'-GGGCCCAGGACTCTATTTTC-3' }\end{array}$ & 62 & 212 \\
\hline DYS273 & $\begin{array}{l}\text { 5'-GCAGTGAGCTGAGATTGTGC-3' } \\
\text { 5'-CTCTACCTCCTTCCCCCAGT-3' }\end{array}$ & 55 & 191 \\
\hline DYS280 & $\begin{array}{l}\text { 5'-GGAGGCTTCATCAGCAAGAC-3' } \\
\text { 5'-CCCCATAATGACATCAGCCTA-3' }\end{array}$ & 55 & 235 \\
\hline DYS1 & $\begin{array}{l}\text { 5'-GTTGAGCCGGTCAAGAAAAA-3' } \\
\text { 5'-CACTGCCCTAATCCTAGCACA-3' }\end{array}$ & 55 & 127 \\
\hline DYS218 & $\begin{array}{l}\text { 5'-TGGTCATGACAAAAGACGAA-3' } \\
\text { 5'-GGCTCACAAACGAAAAGAAA-3' }\end{array}$ & 60 & 274 \\
\hline DYS14 & $\begin{array}{l}\text { 5'-CTGCAGGCAGTAATAAGGGA-3' } \\
\text { 5'-GGCTTCTCATTCCACTCCAA-3' }\end{array}$ & 46 & 312 \\
\hline$D Y Z 3$ & $\begin{array}{l}\text { 5'-CCTCTTCAGGTGGCTTCATC-3' } \\
\text { 5'-TGTGGTATGTGCATTCATCTCA-3' }\end{array}$ & 62 & 188 \\
\hline & 5'-GAATGCGCACAACAAAAAGA-3' & & \\
\hline
\end{tabular}


automated fluorescent sequencer (Applied Biosystems, Foster City, CA, USA) in accordance with the manufacturer's protocols. The sequence data were analyzed using CHROMAS software (Version 1.62; Technelysium, Queensland, Australia), and the sequencing results were compared with human reference sequences from GenBank.

\section{Histochemical Staining}

All patients verified as Y chromosome-positive either by cytogenetic analysis or PCR analysis were offered oophorectomy. Obtained tissues were fixed in formalin buffer, processed in paraffin blocks, and stained with hematoxylin and eosin by the same pathologist. The pathologist examined the tissues to evaluate the presence of gonadoblastoma.

\section{Statistical Analysis}

All statistical calculations were performed with SAS version 9.2 (SAS Institute Inc., Cary, NC, USA). Two-sample Student's $t$ tests were used to compare clinical characteristics between patients with and without $\mathrm{Y}$ chromosome material. Fisher's exact tests were used to evaluate differences between the occurrence of gonadoblastoma in patients with overt $Y$ chromosome and patients with cryptic Y chromosome material. Two-sample $z$ tests were used to evaluate differences between the occurrence rate of gonadoblastoma in the present study and in other studies. Results with two-tailed $P$ values of less than 0.05 were considered statistically significant.

\section{Results}

\section{Frequency of Cryptic Y Chromosome Material in Patients with TS}

PCR analysis with 14 primer pairs targeting Y chromosomespecific sequences identified 16 patients with $\mathrm{Y}$ chromosome material. In six of these patients, the presence of the Y chromosome was confirmed by karyotyping, whereas in the remaining 10 patients, $\mathrm{Y}$ chromosome material was only detected by PCR (Table 3). Cryptic Y chromosome material was found in $8.5 \%$ ( 10 out of 118) of patients whose karyotype did not suggest the presence of the Y chromosome (Fig. 1).

\section{Clinical Characteristics of Patients with TS with or without Y Chromosome Material}

All patients who had Y chromosome material, whether overt $\mathrm{Y}$ chromosome or cryptic Y chromosome material, showed normal female external genitalia and had female internal genital organs. Table 4 shows the clinical characteristics of patients with TS with or without Y chromosome material. There were no significant differences between the two groups.

Table 3 PCR data for 16 patients with Y chromosome material

\begin{tabular}{|c|c|c|c|c|c|c|c|c|c|c|c|c|c|c|c|c|c|c|}
\hline Patient & Karyotype & Age (year) & $1^{\mathrm{a}}$ & 2 & 3 & 4 & 5 & 6 & 7 & 8 & 9 & 10 & 11 & 12 & 13 & 14 & Oophorectomy & Gonadoblastoma \\
\hline No. 2 & $46, X, \operatorname{del}(x)(q 11)$ & 14 & $+{ }^{\mathrm{b}}$ & + & + & + & + & + & + & + & + & + & + & + & + & + & + & + \\
\hline No. 19 & $45, \mathrm{X} / 46, \mathrm{XY}[57 \%]$ & 12 & + & + & - & + & + & + & + & + & + & + & + & + & + & + & + & - \\
\hline No. 31 & $45, \mathrm{X} / 46, \mathrm{XY}[83 \%]$ & 9 & + & + & - & + & - & + & - & + & + & + & - & + & + & + & + & - \\
\hline No. 43 & $45, \mathrm{X} / 46, \mathrm{X},+\mathrm{mar}$ & 19 & + & + & - & + & + & + & + & + & + & + & - & + & + & + & + & - \\
\hline No. 57 & $45, \mathrm{X}$ & 13 & - & - & + & - & - & - & - & - & - & - & - & + & - & - & - & - \\
\hline No. 68 & $45, \mathrm{X} / 46, \mathrm{XY}[91 \%]$ & 20 & + & + & + & + & + & + & + & + & + & + & + & + & + & + & + & - \\
\hline No. 77 & $45, \mathrm{X}$ & 13 & + & + & - & + & - & + & - & + & + & + & - & - & + & + & + & + \\
\hline No. 82 & $45, \mathrm{X} / 46, \mathrm{XY}[75 \%]$ & 31 & + & + & + & + & + & + & - & + & + & + & + & + & + & + & + & - \\
\hline No. 90 & $46, \mathrm{XX} / 46, \mathrm{X}, \mathrm{i}(\mathrm{Xq})$ & 31 & - & - & + & - & - & - & - & - & - & - & - & - & - & - & - & - \\
\hline No. 91 & 46,X,i(X)(q10) & 31 & - & - & + & - & - & - & - & - & - & - & - & - & - & - & - & - \\
\hline No. 97 & $45, X / 46, X, i(X q)$ & 30 & - & - & + & - & - & - & - & - & - & - & - & - & - & - & + & - \\
\hline No. 106 & $45, \mathrm{X} / 46, \mathrm{X}, \mathrm{r}(\mathrm{X})$ & 5 & - & - & - & - & - & - & - & - & + & - & - & - & - & - & - & - \\
\hline No. 108 & $45, \mathrm{X} / 46, \mathrm{X},+\mathrm{mar}$ & 27 & + & + & + & + & + & + & + & + & + & + & + & + & + & + & - & - \\
\hline No. 113 & $45, \mathrm{X} / 46, \mathrm{XY}[33 \%]$ & 24 & + & + & + & + & + & + & + & + & + & + & + & + & + & + & + & - \\
\hline No. 123 & $46, X, i(X q)$ & 18 & + & - & + & + & + & + & - & - & - & - & + & + & - & - & - & - \\
\hline No. 124 & $45, \mathrm{X} / 46, \mathrm{XY}[82 \%]$ & 31 & + & + & + & + & + & + & + & + & + & + & + & + & + & + & + & + \\
\hline
\end{tabular}

${ }^{a} Y$ chromosome-specific sequences are numbered as follows: 1, PABY; 2, SRY; 3, DYZ1; 4, DYS231; 5, DYS209; 6, YRRM; 7, DYS224; 8, AMGY; 9, DYS273; 10, DYS280; 11, DYS1; 12, DYS218; 13, DYS14; 14, DYZ3

${ }^{\mathrm{b}}(+)$ indicates amplification, surgical procedure, or neoplasm, as appropriate. (-) indicates no amplification, no surgical procedure, or no neoplasm, as appropriate 
Table 4 Clinical characteristics of patients with TS with or without Y chromosome material

\begin{tabular}{llll}
\hline & $\begin{array}{l}\text { Y chromosome material } \\
\text { negative group }\end{array}$ & $\begin{array}{l}\text { Y chromosome material } \\
\text { positive group }\end{array}$ & $P$ value \\
\hline Patient number & $108(87.1 \%)$ & $16(12.9 \%)$ & \\
Age at study (years) & $17.75 \pm 8.93$ & $20.61 \pm 9.17$ & 0.240 \\
Height SDS & $-3.27 \pm 1.59$ & $-3.08 \pm 1.68$ & 0.666 \\
Weight SDS & $-0.99 \pm 1.01$ & $-0.84 \pm 1.11$ & 0.596 \\
BMI $\left(\mathrm{kg} / \mathrm{m}^{2}\right)$ & $18.40 \pm 3.55$ & $19.30 \pm 4.79$ & 0.371 \\
Dysmorphic features $^{\mathrm{a}}$ & $88(81.5 \%)$ & $10(62.5 \%)$ & 0.132 \\
Short stature & $82(75.9 \%)$ & $13(81.3 \%)$ & 0.692 \\
Delayed puberty $^{\mathrm{c}}$ & $20(18.5 \%)$ & $4(25.0 \%)$ & 0.727 \\
Osteopenia $^{\mathrm{d}}$ & $25(23.1 \%)$ & $4(25.0 \%)$ & 0.854 \\
Cardiac anomalies $^{\text {Renal anomalies }}$ & $10(9.3 \%)$ & $1(6.3 \%)$ & 0.693 \\
Diabetes mellitus or Impaired $_{\quad}$ glucose tolerance & $10(9.3 \%)$ & $2(12.5 \%)$ & 0.857 \\
Hypothyroidism & $2(1.9 \%)$ & $1(6.3 \%)$ & 0.492 \\
\hline
\end{tabular}

Age, height SDS, weight SDS, and BMI are presented as means \pm standard deviations. All other items, including short stature, are presented as the percentage of total patients (\%)

SDS standard deviation score, $B M I$ body mass index

${ }^{a}$ Dysmorphic features: short webbed neck, low hairline, low-set ears, broad chest, multiple pigmented nevi, cubitus valgus, swollen or puffy hands or feet, and knuckle knuckle sign

${ }^{\mathrm{b}}$ Short stature: patient's height below 2 standard deviations compared with that of individuals of the same sex and age in the normal Korean population

${ }^{\mathrm{c}}$ Delayed puberty: no breast development by either chronologic age 13 or no menstruation for 5 or more years after the first appearance of breast tissue

${ }^{\mathrm{d}}$ Osteopenia: $z$-score under -1.0 relative to those of individuals of the same age and sex in bone mineral density for patients under 18 years, $T$-score lower than -1.0 in bone mineral density for patients 19 years or older

\section{Occurrence of Gonadoblastoma in Patients with TS}

All six patients with $\mathrm{Y}$ chromosome material verified by karyotyping underwent oophorectomy before joining this study, whereas 4 of 10 patients with Y chromosome material verified only by molecular methods underwent oophorectomy after the analysis. The remaining six patients with Y chromosome material verified by PCR analysis chose not to have oophorectomy because of personal preference or prepubertal age. All gonadal tissues obtained from these 10 patients consisted of ovarian tissues, not testicular tissues. Pelvic ultrasound sonography performed before oophorectomy did not suggest gonadoblastoma in these patients. Gonadoblastoma was diagnosed on the basis of light microscopic pathological evaluation of the ovaries. Of the 10 patients with oophorectomy, three patients were diagnosed with gonadoblastoma. Thus, the overall occurrence of gonadoblastoma in patients with TS was $2.4 \%$ (3 out of 124 patients). One case of gonadoblastoma was confirmed among patients with $\mathrm{Y}$ chromosome verified by karyotyping (one in six patients with overt $Y$ chromosome, $16.6 \%$; Fig. 1). This patient was diagnosed with TS at 10 years of age, and her karyotype was $45, \mathrm{X} / 46, \mathrm{XY}[82 \%]$. She did not exhibit spontaneous puberty and was treated with oral estradiol. She underwent oophorectomy at 31 years of age. She had not undergone any imaging analyses before oophorectomy and underwent oophorectomy only because of the presence of overt $\mathrm{Y}$ chromosome material. The ovaries measured $2.0 \times 1.5 \times 0.7 \mathrm{~cm}$ on the left and $3.2 \times 0.6 \times 0.2 \mathrm{~cm}$ on the right. Gonadoblastoma with multifocal calcified substances and dense fibrosis without any viable tumor cells were observed in the left ovary.

Two cases of gonadoblastoma were confirmed among patients with Y chromosome material verified by PCR (2 in 10 patients with cryptic $\mathrm{Y}$ chromosome material, 20\%; Fig. 1). One case was diagnosed with TS, with the 46,X,del(x)(q11) karyotype, at 6 years of age. She enrolled in this study, and cryptic $\mathrm{Y}$ chromosome material was discovered (Table 3). She did not experience spontaneous puberty and was administered estradiol replacement therapy at 12 years of age. We recommended oophorectomy; accordingly, she underwent oophorectomy at 14 years of age, even though her pelvic ultrasonography findings were normal. The right ovary $(2.0 \times 0.5 \times 0.3 \mathrm{~cm})$ showed normal findings, and the left ovary $(2.0 \times 1.0 \times 0.3 \mathrm{~cm})$ included a gonadoblastoma measuring $0.4 \mathrm{~cm}$ in size. The other case was diagnosed with TS at 12 years of age, with the pure $45, \mathrm{X}$ karyotype. She enrolled in this study at 13 years of age, and cryptic Y chromosome material was also discovered (Table 3). At that time, her Tanner stage was 3 with spontaneous breast development 4 years prior, but without menarche. She underwent 
oophorectomy, even though pelvic ultrasonography findings were normal. Her left ovary measured $0.8 \times 0.5 \times 0.3 \mathrm{~cm}$ and showed rudimentary ovarian tissue with mature fallopian tubes. However, several calcified nodules, which were suggested to represent regressing gonadoblastoma, were observed in the right rudimentary ovarian tissue (size, $1.5 \times 1.0 \times 0.5 \mathrm{~cm}$ ).

The occurrences of gonadoblastoma in patients with overt $\mathrm{Y}$ chromosome (16.6\%) and patients with Y chromosome material verified by PCR (20\%) were not significantly different (Table 5). This result was similar to that in previous studies, with the exception of three studies that did not describe the occurrence of gonadoblastoma in patients with overt $\mathrm{Y}$ chromosome; we summarized the results of the other studies in Table 5. In addition, compared with other studies, the occurrence rate of gonadoblastoma in patients with cryptic Y chromosome material was similar, except for two studies that showed even higher rates than our study (Table 5).

\section{Discussion}

We investigated the frequency of cryptic $\mathrm{Y}$ chromosome material in 118 patients with TS in whom cytogenetic karyotyping did not reveal overt Y chromosome. We compared gonadoblastoma occurrence in these patients with that in patients with TS harboring the Y chromosome confirmed by karyotyping. PCR analysis identified cryptic Y chromosomal material in 10 out of 118 patients with TS without overt Y chromosome on karyotyping (8.5\%). This is consistent with the previously reported range of $3-38 \%$ [6-8, 27, 28].
Previously, 3.1 and $4.8 \%$ of patients with TS with a pure 45,X karyotype were found to have Y-specific material by PCR in Mexican and Brazilian studies, respectively [6, 27]. In a study conducted in the Netherlands, $7.9 \%$ of patients with TS with the 45,X karyotype had a derivative $\mathrm{Y}$ chromosome by FISH analysis [28]. Y-specific material was detected in $16.6 \%$ of patients with the $45, \mathrm{X}$ or $45, \mathrm{X} / 46, \mathrm{XX}$ karyotype in another study in the USA [7]. A Russian study reported a 38\% detection rate for Y-specific sequences by PCR in patients without overt $Y$ chromosome [8]. The variability in the reported frequencies of cryptic $\mathrm{Y}$ chromosome material may stem from differences in the molecular methodologies, ethnicity, tissues tested, Y chromosome-specific primers used, and number of patients with a mosaic marker chromosome.

The approach of verifying the presence of cryptic Y chromosome material in all patients with TS should be established only after evaluating the risk of gonadoblastoma development in patients with TS with overt and cryptic Y chromosome material. A previous meta-analysis of 11 studies investigating this topic revealed gonadoblastoma in 5 of $557(0.9 \%)$ patients with TS and 5 of 43 (11.6\%) patients with TS bearing a Y chromosomal cell line (16 patients with overt $\mathrm{Y}$ chromosome and 27 patients with cryptic Y chromosome material) [13]. Based on these findings, the author concluded that routine PCR examination of all patients with TS was not required to identify individuals at high risk of gonadoblastoma development. In 2007, the Turner Syndrome Study Group recommended that testing for $\mathrm{Y}$ chromosome material should be performed in patients with TS using a marker chromosome, i.e., a sex chromosomal fragment of unknown origin, and with the presence of

Table 5 Summary of studies on the occurrence of gonadoblastoma in patients with TS with overt $\mathrm{Y}$ chromosome and cryptic $\mathrm{Y}$ chromosome material

\begin{tabular}{|c|c|c|c|c|c|c|}
\hline Reference & $\begin{array}{l}\text { Total patient } \\
\text { nos. }\end{array}$ & $\begin{array}{l}\text { Patients with } \\
\text { overt Y Chr }\end{array}$ & $\begin{array}{l}\text { Patients without } \\
\text { overt Y Chr }\end{array}$ & $\begin{array}{l}\text { Patients with cryptic } \\
\text { Y Chr material (\%) }\end{array}$ & $\begin{array}{l}\text { Gonadoblastoma } \\
\text { in patients with } \\
\text { overt Y Chr (\%) }\end{array}$ & $\begin{array}{l}\text { Gonadoblastoma in } \\
\text { patients with cryptic } \\
\text { Y Chr material (\%) }\end{array}$ \\
\hline Present study & 124 & 6 & 118 & $10 / 118(8.5)$ & $1 / 6(16.6)$ & $2 / 10(20.0)$ \\
\hline Zelaya et al. $[15]^{\mathrm{a}}$ & 217 & 20 & 197 & $3 / 197(1.5)$ & $5 / 20(25.0)$ & $1 / 3(33.3)$ \\
\hline Silveri et al. $[16]^{\mathrm{a}, \mathrm{b}}$ & 84 & 3 & 81 & $3 / 81(3.7)$ & $3 / 3(100.0)$ & $3 / 3(100.0)$ \\
\hline Barros et al. $[17]^{\mathrm{a}}$ & 260 & 6 & 254 & $10 / 254(3.9)$ & $0 / 6(0)$ & $0 / 10(0)$ \\
\hline Sallai et al. $[18]^{\mathrm{a}}$ & 130 & 3 & 127 & $6 / 127(4.7)$ & $1 / 3(33.3)$ & $0 / 6(0)$ \\
\hline Bianco et al. [19] & 87 & 0 & 87 & $16 / 87(18.4)$ & NA & $2 / 16(12.5)$ \\
\hline Mazzanti et al. $[20]^{\mathrm{a}}$ & 171 & 10 & 161 & $4 / 161(2.5)$ & $2 / 10(20.0)$ & $2 / 4(50.0)$ \\
\hline Canto et al. [21] & 107 & 0 & 107 & $10 / 107(9.3)$ & NA & $2 / 10(20.0)$ \\
\hline Mancilla et al. $[22]^{\mathrm{a}}$ & 58 & 2 & 56 & $2 / 56(3.6)$ & $1 / 2(50.0)$ & $1 / 2(50.0)$ \\
\hline Alvarez-Nava et al. [23] $]^{\mathrm{a}, \mathrm{b}}$ & 52 & 2 & 50 & $2 / 50(4.0)$ & $0 / 2(0)$ & $2 / 2(100.0)$ \\
\hline Gravholt et al. [24] ${ }^{\mathrm{a}}$ & 114 & 7 & 107 & $7 / 107(6.5)$ & $1 / 7(14.3)$ & $0 / 7(0)$ \\
\hline Mendes et al. [25] & 36 & 0 & 36 & $2 / 36(5.6)$ & NA & $1 / 2(50.0)$ \\
\hline López et al. [26] & 50 & 1 & 49 & $6 / 49(12.2)$ & $0 / 1(0)$ & $1 / 6(16.7)$ \\
\hline
\end{tabular}

Chr chromosome, NA not available

${ }^{a}$ The occurrences of gonadoblastoma were not different between patients with overt $\mathrm{Y}$ chromosome and patients with cryptic $\mathrm{Y}$ chromosome material

${ }^{\mathrm{b}}$ The occurrence rate of gonadoblastoma in patients with cryptic $\mathrm{Y}$ chromosome material was significantly different for the present study $(P<0.001)$ 
virilization [3]. The guidelines also indicated that there is no need for routine testing for SRY or the presence of Y chromosome material in $45, \mathrm{X}$ individuals without masculinization. Recently, many studies have reported molecular identification of Y chromosome material in patients with TS without overt $Y$ chromosome and in the absence of virilization or a marker chromosome. This suggested the necessity of cryptic Y chromosome material screening in all patients with TS. Moreover, some investigators have reported a high prevalence (18-100\%) of gonadoblastoma in patients with cryptic Y chromosome material and proposed that measures should be taken to evaluate cryptic $\mathrm{Y}$ chromosome material in all patients with TS [19, 23]. In the present study, we demonstrated the occurrence of gonadoblastoma in 3 of 124 (2.4\%) patients with TS. One gonadoblastoma case was identified in six patients with overt Y chromosome (16.6\%) and two gonadoblastoma cases were found in 10 patients with cryptic Y chromosome material (20.0\%). This finding suggested that patients with TS with cryptic Y chromosome material are at a similar risk of developing gonadoblastoma as patients with TS with an overt $\mathrm{Y}$ chromosome. To assess the risk of gonadoblastoma development in patients with TS with cryptic Y chromosome material, we reviewed 12 previous studies investigating this topic [15-26] and integrated our current study results. None of the studies observed a difference in the gonadoblastoma rate between patients with overt versus cryptic $\mathrm{Y}$ chromosome material, except three studies for which no data on the presence of overt $\mathrm{Y}$ chromosome were available (Table 5). The occurrence rates of gonadoblastoma in patients with cryptic $\mathrm{Y}$ chromosome material between the present study and other studies were also similar, except for two studies that showed even higher occurrence rates of gonadoblastoma (Table 5). Based on these data, including our results, we concluded that testing for cryptic Y chromosome material should be recommended for all patients with TS to detect individuals at high risk of developing gonadoblastoma.

Even though more genes were examined in the present study than in other studies, 14 genes derived from the Y chromosome do not represent all of the $\mathrm{Y}$ chromosome. In particular, we did not analyze the testis-specific protein Y-encoded (TSPY) gene, which has recently been identified as a gonadoblastoma candidate gene [29, 30]. The TSPY repeat gene has been reported as a putative gene of the gonadoblastoma locus on the $\mathrm{Y}$ chromosome (GBY locus) and has been shown to be associated with various forms of human cancers, including gonadoblastoma, leukemia, lung cancer, melanoma, and hepatocellular carcinoma [29]. Indeed, high levels of TSPY protein and germ cell tumor markers have been observed in gonadoblastoma tissue specimens obtained from patients with TS [30-32]. Recently, many researchers have attempted to identify genes responsible for gonadoblastoma and have emphasized the necessity for a more sensitive screening method to determine the risk of gonadoblastoma in patients with TS. Therefore, further studies are needed to determine whether detection of the TSPY gene in the peripheral lymphocytes of patients with TS is associated with an increased risk of gonadoblastoma.

Although many patients enrolled in this study and the results were similar to other studies, the present study was carried out at a single center, and the occurrence rate of gonadoblastoma cannot be regarded as representative of that in the entire population. Furthermore, in other studies, patients with TS without overt $\mathrm{Y}$ chromosome in blood lymphocytes were often found to have derivative $\mathrm{Y}$ chromosome material in various other tissues, such as buccal cells and gonadal tissue $[27,28]$. Because the results of the rate of cryptic Y chromosome material are inconsistent between blood lymphocytes and other tissues and the exact mechanism of gonadoblastoma development remains to be elucidated, the karyotype of ovarian tissue and the presence of cryptic $\mathrm{Y}$ chromosome material in the gonads are important. However, our objective was to evaluate the association between cryptic $\mathrm{Y}$ chromosome material detected by PCR in blood samples and gonadoblastoma in patients with TS; therefore, we did not analyze Y chromosome material in other tissues besides the gonads. These are considered limitations of the present study.

In summary, the present study demonstrated that the frequency of cryptic $\mathrm{Y}$ chromosome material in patients with TS without overt Y chromosome was $8.5 \%$. The overall occurrence of gonadoblastoma in this study group was three in 124 $(2.4 \%)$. The occurrence of gonadoblastoma in patients with TS with cryptic $\mathrm{Y}$ chromosome material was similar to that in patients with TS with overt $\mathrm{Y}$ chromosome (16.6 versus $20.0 \%$ ). This suggested that screening for cryptic Y chromosome material should be recommended for all patients with TS to detect individuals at high risk of gonadoblastoma development.

Acknowledgements This study received grant support from Novo Nordisk Pharma Ltd. Grant-2012 (H.-S. Kim) and partial grant support from Yonsei University College of Medicine 6-2012-0116.

\section{Compliance with Ethical Standards}

Disclosure Summary The authors have nothing to disclose.

\section{References}

1. Turner HH (1938) A syndrome of infantilism, congenital webbed neck, and cubitus valgus. Endocrinology 23:566-574

2. Nielsen J, Wohlert M (1991) Chromosome abnormalities found among 34,910 newborn children: results from a 13-year incidence study in Arhus, Denmark. Hum Genet 87(1):81-83

3. Bondy CA (2007) Care of girls and women with Turner syndrome: a guideline of the Turner Syndrome Study Group. J Clin Endocrinol Metab 92(1):10-25 
4. Pinsker JE (2012) Clinical review: Turner syndrome: updating the paradigm of clinical care. J Clin Endocrinol Metab 97(6):E9941003

5. Lippe B (1991) Turner syndrome. Endocrinol Metab Clin N Am 20(1):121-152

6. Araujo C, Galera MF, Galera BB, Silvestre FG, Medeiros SF (2008) Molecular identification of chromosome Y sequences in Brazilian patients with Turner syndrome. Gynecol Endocrinol 24(12):713-717

7. Kocova M, Siegel SF, Wenger SL, Lee PA, Trucco M (1993) Detection of Y chromosome sequences in Turner's syndrome by southern blot analysis of amplified DNA. Lancet 342(8864):140 143

8. Osipova GR, Karmanov ME, Kozlova SI, Evgrafov OV (1998) PCR detection of Y-specific sequences in patients with UllrichTurner syndrome: clinical implications and limitations. Am J Med Genet 76(4):283-287

9. Modi D, Bhartiya D (2007) Y chromosome mosaicism and occurrence of gonadoblastoma in cases of Turner syndrome and amenorrhoea. Reprod BioMed Online 15(5):547-553

10. Wiktor AE, Van Dyke DL (2005) Detection of low level sex chromosome mosaicism in Ullrich-Turner syndrome patients. Am J Med Genet A 138a(3):259-261

11. Brant WO, Rajimwale A, Lovell MA, Travers SH, Furness PD 3rd, Sorensen M, Oottamasathien S, Koyle MA (2006) Gonadoblastoma and Turner syndrome. J Urol 175(5):1858-1860

12. Hsu LY (1994) Phenotype/karyotype correlations of Y chromosome aneuploidy with emphasis on structural aberrations in postnatally diagnosed cases. Am J Med Genet 53(2):108-140

13. Cools M, Drop SL, Wolffenbuttel KP, Oosterhuis JW, Looijenga LH (2006) Germ cell tumors in the intersex gonad: old paths, new directions, moving frontiers. Endocr Rev 27(5):468-484

14. Semerci CN, Satiroglu-Tufan NL, Turan S, Bereket A, Tuysuz B, Yilmaz E, Kayserili H, Karaman B, Semiz S, Duzcan F et al (2007) Detection of Y chromosomal material in patients with a 45,X karyotype by PCR method. Tohoku J Exp Med 211(3):243-249

15. Zelaya G, Lopez Marti JM, Marino R, Garcia de Davila MT, Gallego MS (2015) Gonadoblastoma in patients with UllrichTurner syndrome. Pediatr Dev Pathol 18(2):117-121

16. Silveri M, Grossi A, Bassani F, Orazi C, Camassei FD, Zaccara A (2016) Ullrich-Turner syndrome and tumor risk: is there another chance to early gonadectomy in positive TSPY and SRY patients? Eur J Pediatr Surg 26(3):273-276

17. Barros BA, Moraes SG, Coeli FB, Assumpcao JG, De Mello MP, Maciel-Guerra AT, Carvalho AB, Viguetti-Campos N, Vieira TA, Amstalden EM et al (2011) OCT4 immunohistochemistry may be necessary to identify the real risk of gonadal tumors in patients with Turner syndrome and Y chromosome sequences. Hum Reprod 26(12):3450-3455

18. Sallai A, Solyom J, Dobos M, Szabo J, Halasz Z, Sagodi L, Niederland T, Kozari A, Bertalan R, Ugocsai P et al (2010) Ychromosome markers in Turner syndrome: screening of 130 patients. J Endocrinol Investig 33(4):222-227

19. Bianco B, Lipay M, Guedes A, Oliveira K, Verreschi IT (2009) SRY gene increases the risk of developing gonadoblastoma and/ or nontumoral gonadal lesions in Turner syndrome. Int J Gynecol Pathol 28(2):197-202

20. Mazzanti L, Cicognani A, Baldazzi L, Bergamaschi R, Scarano E, Strocchi S, Nicoletti A, Mencarelli F, Pittalis M, Forabosco A et al (2005) Gonadoblastoma in Turner syndrome and Y-chromosomederived material. Am J Med Genet A 135(2):150-154

21. Canto P, Kofman-Alfaro S, Jimenez AL, Soderlund D, Barron C, Reyes E, Mendez JP, Zenteno JC (2004) Gonadoblastoma in Turner syndrome patients with nonmosaic 45, $\mathrm{X}$ karyotype and $\mathrm{Y}$ chromosome sequences. Cancer Genet Cytogenet 150(1):70-72

22. Mancilla EE, Poggi H, Repetto G, Rumie H, Garcia H, Ugarte F, Hidalgo S, Jara A, Muzzo S, Panteon E et al (2003) Y chromosome sequences in Turner's syndrome: association with virilization and gonadoblastoma. J Pediatr Endocrinol Metab 16(8):1157-1163

23. ALvarez-Nava F, Soto M, Sanchez MA, Fernandez E, Lanes R (2003) Molecular analysis in Turner syndrome. J Pediatr 142(3): 336-340

24. Gravholt CH, Fedder J, Naeraa RW, Muller J (2000) Occurrence of gonadoblastoma in females with Turner syndrome and $\mathrm{Y}$ chromosome material: A population study. J Clin Endocrinol Metab 85(9): 3199-3202

25. Mendes JR, Strufaldi MW, Delcelo R, Moises RC, Vieira JG, Kasamatsu TS, Galera MF, Andrade JA, Verreschi IT (1999) Ychromosome identification by PCR and gonadal histopathology in Turner's syndrome without overt Y-mosaicism. Clin Endocrinol 50(1):19-26

26. Lopez M, Canto P, Aguinaga M, Torres L, Cervantes A, Alfaro G, Mendez JP, Kofman-Alfaro S (1998) Frequency of Y chromosomal material in Mexican patients with Ullrich-Turner syndrome. Am J Med Genet 76(2):120-124

27. Cortes-Gutierrez EI, Herrera-Bartolo R, Davila-Rodriguez MI, Palacios-Saucedo GC, Vargas-Villarreal J, Romero-Villarreal JB (2012) Molecular detection of cryptic Y-chromosomal material in patients with Turner syndrome. Oncol Rep 28(4):1205-1210

28. Freriks K, Timmers HJ, Netea-Maier RT, Beerendonk CC, Otten BJ, van Alfen-van der Velden JA, Traas MA, Mieloo H, van de Zande GW, Hoefsloot LH et al (2013) Buccal cell FISH and blood PCR-Y detect high rates of $X$ chromosomal mosaicism and $Y$ chromosomal derivatives in patients with Turner syndrome. European journal of medical genetics 56(9):497-501

29. Lau YF, Li Y, Kido T (2009) Gonadoblastoma locus and the TSPY gene on the human Y chromosome. Birth Defects Res C Embryo Today 87(1):114-122

30. Hildenbrand R, Schroder W, Brude E, Schepler A, Konig R, Stutte HJ, Arnemann J (1999) Detection of TSPY protein in a unilateral microscopic gonadoblastoma of a Turner mosaic patient with a Yderived marker chromosome. J Pathol 189(4):623-626

31. Li Y, Vilain E, Conte F, Rajpert-De Meyts E, Lau YF (2007) Testisspecific protein Y-encoded gene is expressed in early and late stages of gonadoblastoma and testicular carcinoma in situ. Urol Oncol 25(2):141-146

32. Bianco B, Oliveira KC, Guedes AD, Barbosa CP, Lipay MV, Verreschi IT (2010) OCT4 gonadal gene expression related to the presence of Y-chromosome sequences in Turner syndrome. Fertil Steril 94(6):2347-2349 